\title{
Phase Relations, Activities and Minor Element Distribution in Cu-Fe-S and Cu-Fe-S-As Systems Saturated with Carbon at $1473 \mathrm{~K}$
}

\author{
Leandro Voisin ${ }^{1, *}$ and Kimio Itagaki ${ }^{1}$ \\ ${ }^{1}$ Institute of Multidisciplinary Research for Advanced Materials, Tohoku University, Sendai 980-8577, Japan
}

\begin{abstract}
As a fundamental study to develop a new process for eliminating detrimental arsenic, recovering precious elements from the arsenic-rich matte produced from the copper concentrate, and treating the occasionally generated speiss in nonferrous smelting processes, the phase relations in the $\mathrm{Cu}-\mathrm{Fe}-\mathrm{S}$ and $\mathrm{Cu}-\mathrm{Fe}-\mathrm{S}-\mathrm{As}$ systems saturated with carbon and the distribution of some minor elements between the phases in the miscibility gap, where three equilibrated phases of iron-rich alloy, copper-rich alloy and matte coexist, were investigated at $1473 \mathrm{~K}$ by using a quenching method.

The experimental results were discussed on the basis of activity coefficient of arsenic in the matte phase at different matte grades. By utilizing the obtained data, material balance calculations concerning to the treatment of arsenic-rich matte produced in copper smelting by adding the pig-iron was elaborated and also laboratory scale experiments using industrial matte were carried to corroborate the calculations. By using the phase separation, the recovery of valuable copper, silver and gold into the copper-rich alloy and matte phases as well as the elimination of iron and arsenic into the iron-rich alloy phase for discarding as a harmless and smaller deposit might be feasible. [doi: $10.2320 /$ matertrans.47.2963]
\end{abstract}

(Received May 17, 2006; Accepted October 5, 2006; Published December 15, 2006)

Keywords: phase relations, activity coefficient, arsenic-rich matte, iron-rich alloy, copper-rich alloy, speiss, minor element

\section{Introduction}

The Fe-Cu-S ternary system is fundamental for the copper matte, which is made in the smelting stage as an intermediate product to produce metallic copper from the copper concentrate (ore). The matte, which is produced in oxidative smelting or converting using air or oxygenenriched air as a blowing gas, is basically a mixture of FeS and $\mathrm{Cu}_{2} \mathrm{~S}$ with varying content of copper, which is called "matte grade". In the recent practical operations, the matte with $65-70 \%$ matte grade $(65-70$ mass $\%$ of $\mathrm{Cu})$ is produced in the smelting stage, followed by the converting stage to make white metal $\left(\mathrm{Cu}_{2} \mathrm{~S}\right)$ and finally crude copper (blister copper). Due to an increasing tendency of the arsenic content in the copper ores, the concentration of this element tends to be high in the produced matte, white metal and blister copper. This causes a serious problem in controlling the quality of the final product (cathode copper). Therefore, its elimination before the electro-refining of crude copper is of great concern in the copper production. In this respect, the phase relations and thermodynamic properties in the $\mathrm{Fe}$ $\mathrm{Cu}-\mathrm{S}$-As quaternary system are of very important in discussing the behavior of arsenic in matte smelting and converting. The thermodynamic and phase equilibrium studies in this quaternary system were made by Itagaki et al., ${ }^{1,2)}$ Jalkanen et $a l .{ }^{3)}$ and Mendoza et al. ${ }^{4,5)}$ and these data are useful to evaluate the fractional distribution of arsenic among the matte, slag and gas phases in the copper smelting and converting processes. 6,7 )

On the other hand, the matte phase with deficient sulfur apart from the tie line connecting between $\mathrm{FeS}$ and $\mathrm{Cu}_{2} \mathrm{~S}$ in the $\mathrm{Fe}-\mathrm{Cu}-\mathrm{S}$ ternary diagram is often produced in reductive smelting of the copper concentrate like a blast furnace operation using coke as fuel and reducer or in processing the copper concentrate which contains coal in the bulk. ${ }^{8)}$ In the bottom of the smelting furnace, this sulfur-deficient matte

*Corresponding author, E-mail: lvoisin@mail.tagen.tohoku.ac.jp often coexists with the iron base alloy which is produced due to a very strong reducing condition. This alloy is generally called "furnace residue" or "speiss" when a considerable amount of arsenic is contained in the alloy. In the extreme case of the reducing condition, the iron base alloy is saturated with carbon. Relating to this alloy, the phase relations, activities and distribution of minor elements in the $\mathrm{Fe}-\mathrm{Cu}-\mathrm{As}$ system saturated with carbon was studied by Voisin et al. ${ }^{9 \text { ) }}$

It is also of interest in smelting the copper concentrate in a very strongly reducing condition to know the behavior of matte which is made along with the furnace residue or the speiss. In this respect, the phase relations, activities and distribution of minor elements in the $\mathrm{Cu}-\mathrm{Fe}-\mathrm{S}$-As system saturated with carbon are of great importance in the extreme case of reducing smelting. Additionally, the study of this system will provide the fundamental information on a new process proposed in the author's laboratory to eliminate arsenic from the arsenic-rich matte produced from the copper concentrate containing significant amount of this element. It is considered in the proposed process that the matte is to be reduced with a given amount of molten pig iron at about $1473 \mathrm{~K}$ to produce a molten iron base alloy with a considerable amount of arsenic, but with very few amounts of valuable minor elements such as silver and gold, which can be expected to be discarded as a harmless deposit in the yard.

Hence, the phase relations, the activity of arsenic and the distribution ratios of such minor elements as silver, gold and platinum in the $\mathrm{Fe}-\mathrm{Cu}-\mathrm{S}$ and $\mathrm{Fe}-\mathrm{Cu}-\mathrm{S}-\mathrm{As}$ systems saturated with carbon at $1473 \mathrm{~K}$ were investigated in this study.

\section{Experimental Method and Procedure}

The quenching method combined with the metallographic method, combustion-infrared spectrometry for carbon, electron probe micro analysis (EPMA) and inductively coupled plasma spectrometry (ICP) were used to determine the phase relations and the distribution of the minor elements. 


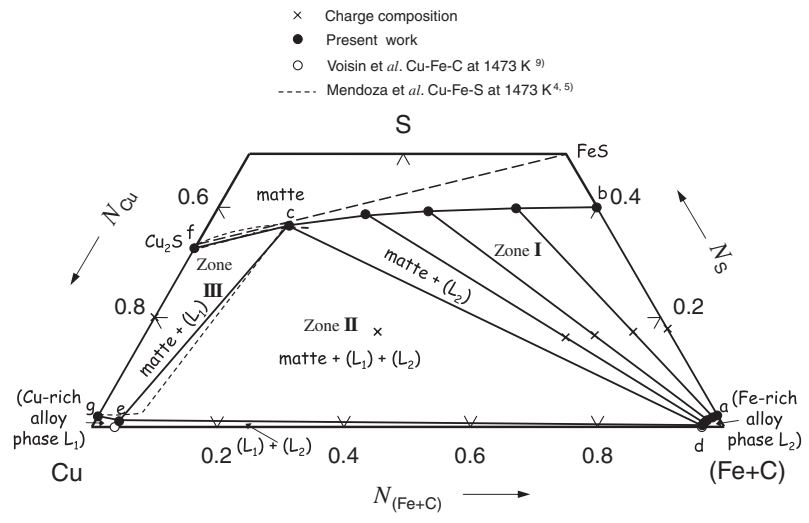

Fig. 1 Phase relations in the $\mathrm{Cu}-(\mathrm{Fe}+\mathrm{C})-\mathrm{S}$ pseudo ternary system saturated with carbon at $1473 \mathrm{~K}$.

\subsection{Phase relations in the $\mathrm{Fe}-\mathrm{Cu}-\mathrm{S}$ and $\mathrm{Fe}-\mathrm{Cu}-\mathrm{S}-\mathrm{As}$ systems saturated with carbon}

The phase relations in the $\mathrm{Fe}-\mathrm{S}-\mathrm{As}-\mathrm{C}$ and $\mathrm{Fe}-\mathrm{Cu}-\mathrm{S}-\mathrm{As}-\mathrm{C}$ systems were determined at $1473 \mathrm{~K}$ as explained later in this work. The compositions of iron, copper and sulfur in the starting samples were fixed at the points shown in Fig. 1 while the content of arsenic in the samples was varied by the addition of $\mathrm{Fe}_{2} \mathrm{As}$.

Two experimental zones were investigated, zone I, where the iron-rich alloy and matte phases are in equilibrium and zone II, where a further copper-rich alloy is equilibrated with the iron-rich alloy and matte phases.

First, in experimental zone I, the four initial experiments without the presence of arsenic were carried out to obtain, for one side, the corresponding equilibrated compositions of the matte and iron-rich alloy phases, and for the other side, enough starting material in the experiments with the presence of arsenic. About $25 \mathrm{~g}$ of sample was prepared by proportionally mixing $\mathrm{FeS}, \mathrm{Cu}_{2} \mathrm{~S}$ and pig iron according to the required charge composition in the $\mathrm{Cu}-\mathrm{Fe}-\mathrm{S}$ system saturated with carbon. $\mathrm{FeS}$ and $\mathrm{Cu}_{2} \mathrm{~S}$ were previously synthesized with iron or copper and sulfur (99.99\% purity) by using a thermal treatment. The sample was charged in a graphite crucible and then it was heated and kept at $1473 \mathrm{~K}$ under an argon atmosphere for $1.8 \mathrm{ks}$ to establish the equilibrium between the two phases, and then it was cooled outside the furnace. For each obtained tie line, four levels of arsenic with 3, 6, 9 and 12 mass percent were evaluated. A $5 \mathrm{~g}$ sample prepared by proportionally mixing $\mathrm{Fe}_{2} \mathrm{As}$ and the previously obtained matte and iron-rich alloy phases, together with a graphite rod, was charged in a $\mathrm{MgO}$ crucible, and then vacuum sealed in a quartz ampoule of $0.09 \mathrm{~m}$ length and $0.026 \mathrm{~m}$ ID. The ampoule was heated and kept at $1473 \mathrm{~K}$ for $21.6 \mathrm{ks}$ to establish the equilibrium between the two phases, and then it was quenched into water. The schematic diagram of experimental apparatus is shown in Fig. 2. The solidified sample was examined by the metallographic analysis and EPMA to confirm the presence of two clearly separated immiscible phases. Once this was confirmed, the two phases were separated with a blade and representative samples were taken for each phase and later analyzed for their components.

For experimental zone II where three equilibrated phases

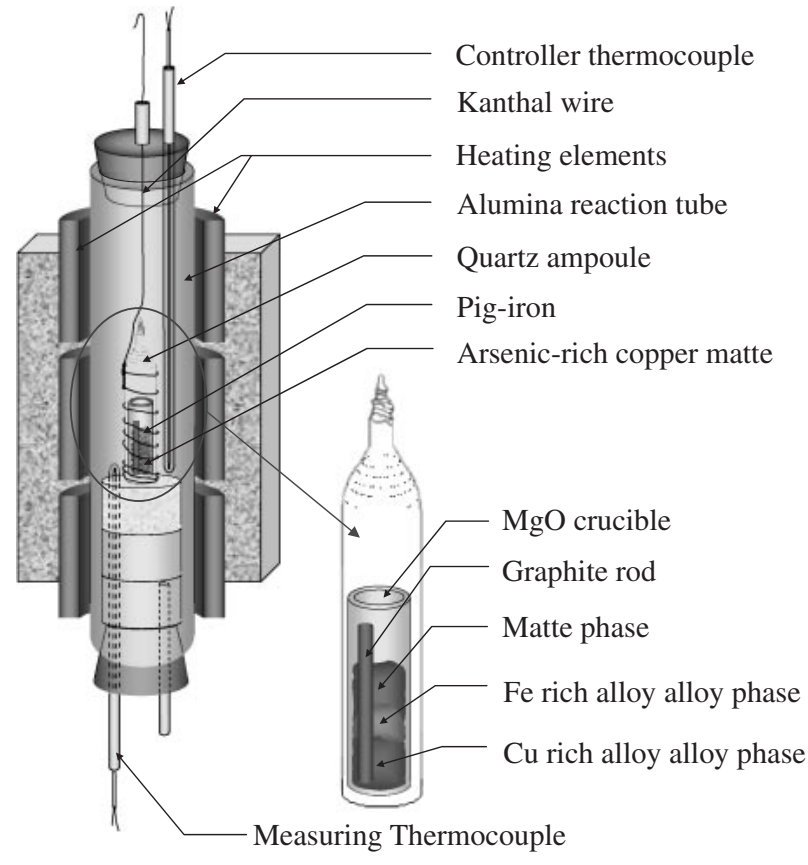

Fig. 2 Schematic diagram of experimental apparatus.

coexist, an $8 \mathrm{~g}$ sample was prepared with different ratios between $\mathrm{Fe}_{2} \mathrm{As}, \mathrm{Cu}_{2} \mathrm{~S}, \mathrm{Cu}$ and pig iron. The experimental procedure was identical to that previously described.

\subsection{Distribution of minor elements in miscibility gap of Fe-Cu-S-As-C system}

Silver, gold and platinum were investigated as minor elements in the region where the equilibrated matte, copperrich alloy and iron-rich alloy equilibrated phases coexist in the $\mathrm{Cu}-\mathrm{Fe}-\mathrm{S}$-As-C system at $1473 \mathrm{~K}$. The mass\% ratio of the total charge, $M_{\mathrm{Cu}} / M_{\mathrm{Fe}} / M_{\mathrm{S}}$, was kept at $27.6 / 62.9 / 9.5$, and the content of arsenic was varied from 0 to 12 mass percent, while the weight composition was 1 mass percent for each minor element. The experimental procedure was identical to that described in 2.1.

\section{Results}

The equilibrium compositions on the tie lines of zones I and II in the $\mathrm{Cu}-\mathrm{Fe}-\mathrm{S}$-As system saturated with carbon at $1473 \mathrm{~K}$ are listed in Tables 1 and 2, respectively. Since the solubility of carbon in the copper-rich alloy and matte phases is very small, the composition diagram for the quaternary system may be simplified to the pseudo-ternary diagram in which iron and carbon are regarded as one constituent. The phase relations in the $\mathrm{Cu}-(\mathrm{Fe}+\mathrm{C})-\mathrm{S}$ pseudo ternary system at $1473 \mathrm{~K}$ are shown in Fig. 1, together with those in the $\mathrm{Cu}-\mathrm{Fe}-$ $\mathrm{S}$ ternary system at $1473 \mathrm{~K}$ in the region where copper-rich alloy and matte phases coexist, which were determined by Mendoza et al. $^{4,5)}$ The phase relations in the $\mathrm{Cu}-\mathrm{Fe}-\mathrm{C}$ ternary system at $1473 \mathrm{~K}$ obtained by Voisin et al. ${ }^{9)}$ were also plotted in the same figure. The composition diagram of $\mathrm{Cu}-$ Fe-S-C quaternary system at $1473 \mathrm{~K}$ is shown in Fig. 3.

3.1 Phase relations in the $\mathrm{Cu}-\mathrm{Fe}-\mathrm{S}-\mathrm{C}$ quaternary system Three different zones were observed in the $\mathrm{Cu}-\mathrm{Fe}-\mathrm{S}$ system 
Table 1 Phase equilibrium compositions of the iron-rich alloy and matte phases in the Cu-Fe-S-As system saturated with carbon at $1473 \mathrm{~K}$ (zone I).

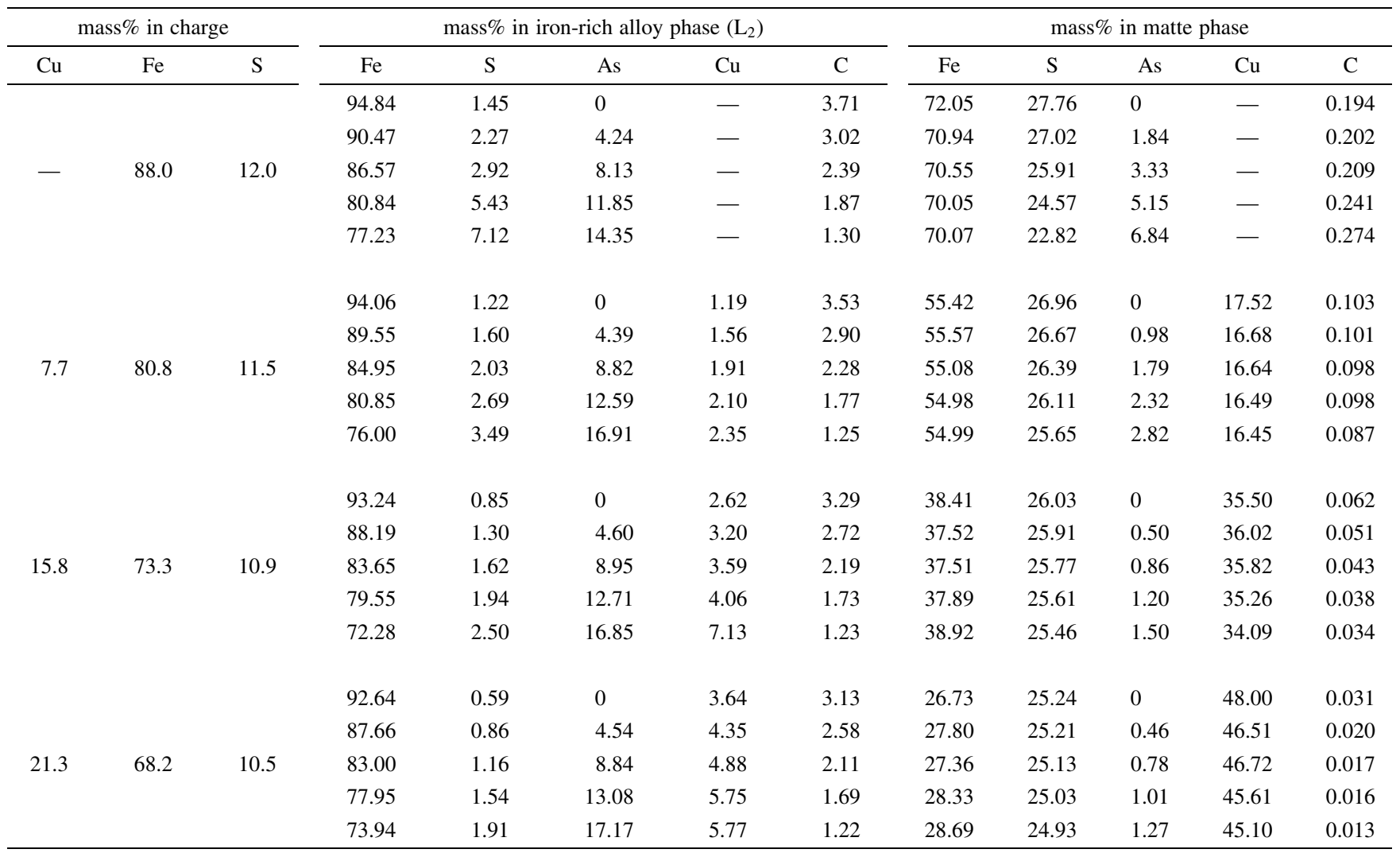

Table 2 Phase equilibrium compositions of the copper-rich alloy, iron-rich alloy and matte phases in the $\mathrm{Cu}-\mathrm{Fe}-\mathrm{S}$-As system saturated with carbon at $1473 \mathrm{~K}$ (zone II).

\begin{tabular}{|c|c|c|c|c|c|c|c|c|c|c|c|c|c|c|}
\hline \multicolumn{5}{|c|}{ mass $\%$ in copper-rich alloy phase $\left(\mathrm{L}_{1}\right)$} & \multicolumn{5}{|c|}{ mass\% in iron-rich alloy phase $\left(\mathrm{L}_{2}\right)$} & \multicolumn{5}{|c|}{ mass $\%$ in matte phase } \\
\hline $\mathrm{Fe}$ & $\mathrm{S}$ & As & $\mathrm{Cu}$ & $\mathrm{C}$ & $\mathrm{Fe}$ & $S$ & As & $\mathrm{Cu}$ & $\mathrm{C}$ & $\mathrm{Fe}$ & $\mathrm{S}$ & As & $\mathrm{Cu}$ & $\mathrm{C}$ \\
\hline 3.41 & 0.58 & 0 & 95.99 & 0.021 & 91.59 & 0.38 & 0 & 4.07 & 3.96 & 13.85 & 23.16 & 0 & 62.95 & 0.047 \\
\hline 8.11 & 0.98 & 8.80 & 82.08 & 0.032 & 85.58 & 0.56 & 5.23 & 5.31 & 3.33 & 14.92 & 22.84 & 0.82 & 61.39 & 0.034 \\
\hline 11.91 & 1.38 & 12.06 & 74.61 & 0.039 & 81.39 & 0.68 & 8.85 & 6.38 & 2.70 & 15.54 & 22.43 & 1.20 & 60.80 & 0.027 \\
\hline 16.56 & 1.71 & 14.27 & 67.42 & 0.042 & 71.58 & 1.12 & 12.62 & 12.77 & 1.92 & 16.57 & 22.29 & 1.40 & 59.73 & 0.016 \\
\hline
\end{tabular}

mass $\% \mathrm{Cu} / \% \mathrm{Fe} / \% \mathrm{~S}$ in charge $=27.6 / 62.9 / 9.5$

saturated with carbon at $1473 \mathrm{~K}$, as shown in Figs. 1 and 3. Zone $\mathrm{I}$ is delimited by points $\mathrm{a}, \mathrm{b}$, c and $\mathrm{d}$ where the iron-rich alloy and matte phases are in equilibrium. Zone II is delimited by points $\mathrm{c}$, d and e where a further copper-rich alloy is equilibrated with the iron-rich alloy and matte phases. Zone III is delimited by points $\mathrm{c}, \mathrm{e}, \mathrm{f}$ and $\mathrm{g}$ where the copperrich alloy and matte phases are in equilibrium.

In the first zone, the slope of the tie lines shifts to the iron side since the presence of carbon in the system makes the iron fusible at the experimental temperature. In zone II, a large miscibility gap is observed. The obtained matte composition with a copper content (matte grade) of 63 mass percent and also the sulfur content in the liquid copper-rich alloy are in a good agreement with those reported by Mendoza et al. ${ }^{4,5)}$ though the solubility of iron in the copper-rich alloy is larger than the reported value. In zone III, the obtained solubility limits of sulfur for the copper-rich alloy and matte phases in

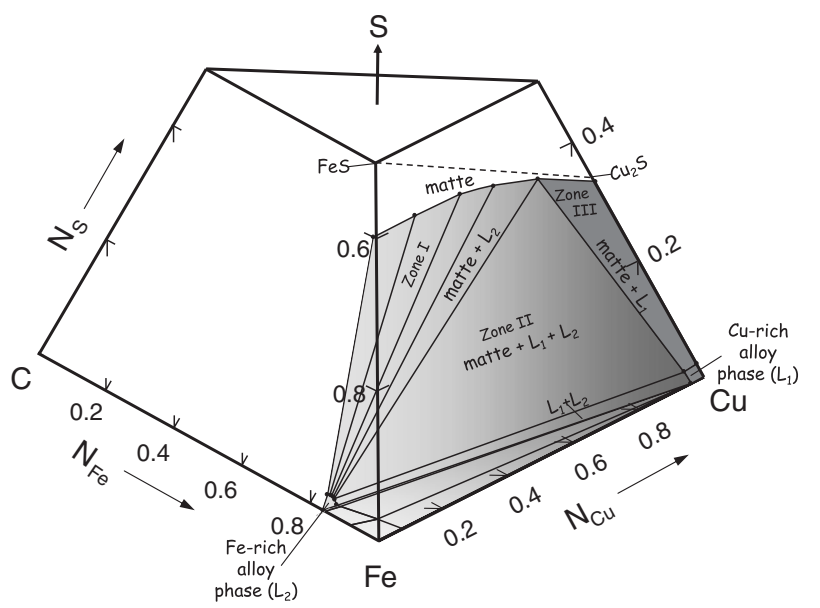

Fig. 3 Phase relations in the $\mathrm{Cu}-\mathrm{Fe}-\mathrm{S}-\mathrm{C}$ quaternary system at $1473 \mathrm{~K}$. 


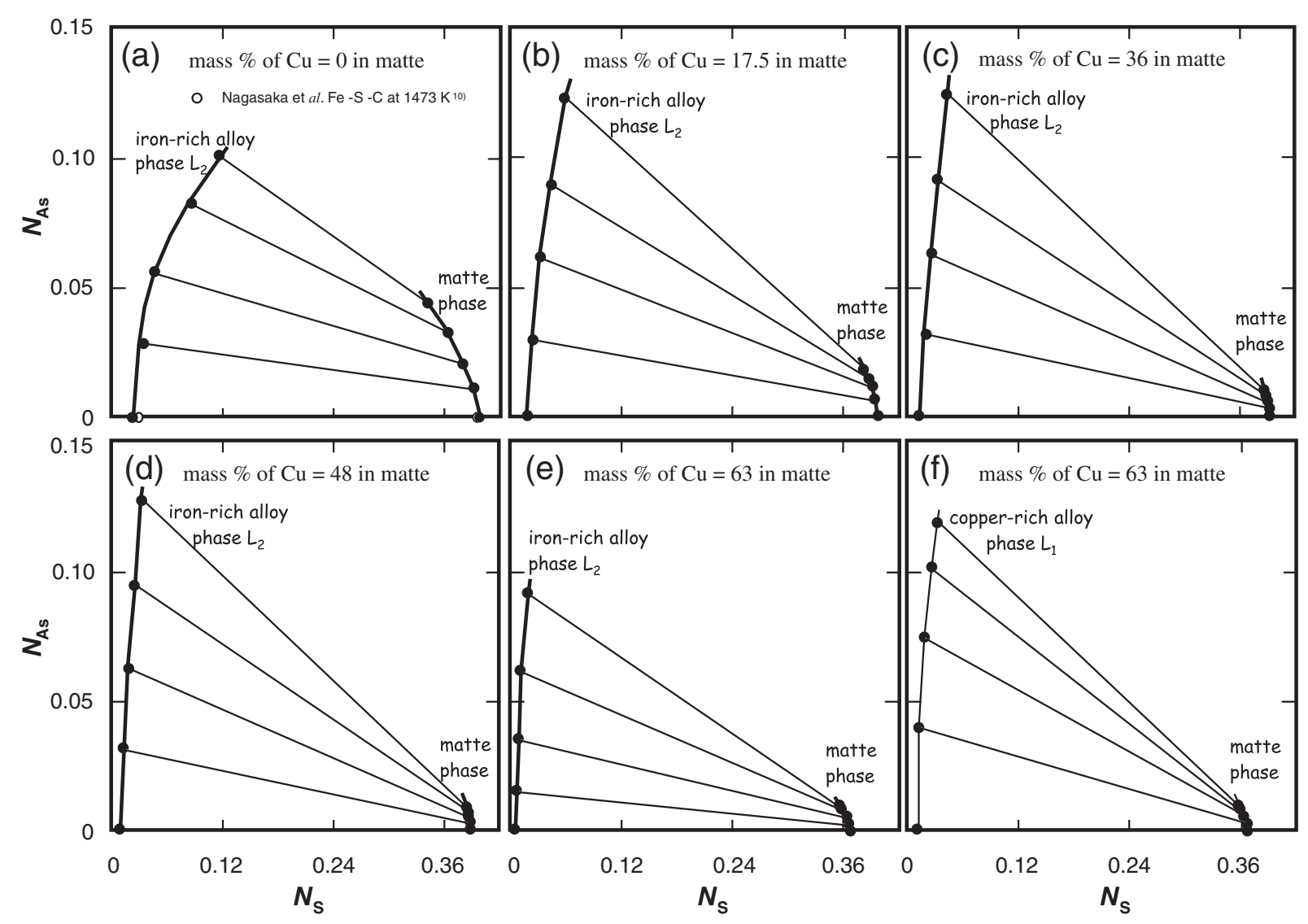

Fig. 4 Relation between $N_{\mathrm{As}}$ and $N_{\mathrm{S}}$ in the iron-rich or copper rich alloy and matte phases in the Fe-S-As and Cu-Fe-S-As systems saturated with carbon at $1473 \mathrm{~K}$.

the $\mathrm{Cu}-\mathrm{S}-\mathrm{C}$ system are in a good agreement with the reported data because the content of carbon in both phases is very small. Furthermore, the data obtained for the $\mathrm{Cu}-\mathrm{Fe}-\mathrm{C}$ system at $1473 \mathrm{~K}$ by the Voisin et al. $^{9)}$ were also plotted in Figs. 1 and 3 and the results are in a good projection toward the obtained points $\mathrm{e}$ and $\mathrm{d}$ in the copper-rich and iron-rich alloys, respectively, in the $\mathrm{Cu}-\mathrm{Fe}-\mathrm{S}$ system saturated with carbon.

\subsection{Phase relations in the $\mathrm{Cu}-\mathrm{Fe}-\mathrm{S}-\mathrm{As}-\mathrm{C}$ system}

The phase relations in the Fe-S-As system saturated with carbon at $1473 \mathrm{~K}$ are shown in Fig. 4(a) in relation to the mole fractions of sulfur $\left(N_{\mathrm{S}}\right)$ and arsenic $\left(N_{\mathrm{As}}\right)$ in both phases. When arsenic is added to the $\mathrm{Fe}-\mathrm{S}$ system saturated with carbon, it is preferentially enriched in the iron-rich alloy with almost the entirety of carbon, while sulfur forms the matte phase with a smaller amount of arsenic and iron when compared with that in the iron-rich alloy. The sulfur content decreases in the matte phase, while increases in the iron-rich alloy with increasing content of arsenic in the charge and also the slope of the tie lines, which connect the two equilibrated phases, increases.

Furthermore, as listed in Table 1, with increasing arsenic amount in the charge, the content of carbon in the iron-rich alloy decreases, while increases in the matte phase. It is important to note that the content of carbon in the matte phase is much smaller than that in the iron-rich alloy. The obtained compositions in this work for the Fe-S-C ternary system are in a good agreement with those reported by Nagasaka et al. ${ }^{10)}$ which are shown together in Fig. 4(a).

The phase relations in the $\mathrm{Fe}-\mathrm{Cu}-\mathrm{S}$-As system saturated with carbon at $1473 \mathrm{~K}$ obtained from the different starting tie lines in zone I, where the matte grades are 17.5, 35.5 and 48 mass\% of $\mathrm{Cu}$, are shown in Figs. 4(b), (c) and (d), respectively, in relation to the mole fractions of sulfur $\left(N_{\mathrm{S}}\right)$ and arsenic $\left(N_{\mathrm{As}}\right)$ in both phases. The corresponding compositions are listed in Table 1. As in the Fe-S-As-C system, arsenic is preferentially enriched in the iron-rich alloy together with carbon, while sulfur and copper in the matte phase with smaller amounts of arsenic and iron when compared with those in the iron-rich alloy phase. The sulfur content decreases in the matte phase, while increases in the iron-rich alloy phase and the slope of the tie lines increases with increasing arsenic content in the charge. While, the carbon content decreases in both phases. With increasing matte grade, the sulfur and carbon contents decrease in both phases.

The phase relations in the $\mathrm{Cu}-\mathrm{Fe}-\mathrm{S}-\mathrm{As}-\mathrm{C}$ system for zone II are shown in Figs. 4(e) and (f) for the iron-rich alloy and matte phases and for the copper-rich alloy and matte phases, respectively, in relation to the mole fractions of sulfur $\left(N_{\mathrm{S}}\right)$ and arsenic $\left(N_{\mathrm{As}}\right)$. While, the corresponding compositions are listed in Table 2.

When arsenic is added to the $\mathrm{Cu}-\mathrm{Fe}-\mathrm{S}-\mathrm{C}$ system in zone II, it is preferentially enriched in the metallic copper-rich and iron-rich alloys with a small amount of sulfur, while sulfur, 
copper and iron form the matte phase with a smaller amount of arsenic when compared with that in the metallic phases. With increasing arsenic content in the charge, the sulfur content decreases in the matte phase and increases in the metallic phases. Furthermore, as listed in Table 2, with increasing arsenic content, the carbon content in the iron-rich alloy decreases, while that in the copper-rich alloy and matte phases increases and decreases, respectively, though they are negligibly small. The copper content in the copper-rich alloy phase decreases with increasing arsenic content, while the iron content increases. On the contrary, the copper content in the iron-rich alloy phase increases with increasing arsenic content while the iron content decreases.

\subsection{Distribution of minor elements in miscibility gap of Cu-Fe-As-C system}

The distribution ratio of a minor element $\mathrm{X}$ between the matte and copper-rich alloy or iron-rich alloy phases in the $\mathrm{Cu}-\mathrm{Fe}-\mathrm{S}-\mathrm{As}$ system saturated with carbon, $L_{\mathrm{X}}{ }^{\mathrm{m} / \mathrm{L}}$, is defined by

$$
L_{\mathrm{X}}^{\mathrm{m} / \mathrm{L}}=[\operatorname{mass} \% \mathrm{X}]_{\mathrm{m}} /\langle\operatorname{mass} \% \mathrm{X}\rangle_{\mathrm{L}},
$$

where []$_{\mathrm{m}}$ and \langle\rangle$_{\mathrm{L}}$ indicate the matte and the iron-rich alloy or copper-rich alloy phases, respectively. By the definition, the element $\mathrm{X}$ will be concentrated in the alloy phase when the value of distribution ratio is less than unity. Hence, a larger value of $L_{X}{ }^{\mathrm{m} / \mathrm{L}}$ corresponding to the iron-rich alloy phase and a smaller one corresponding to the copper-rich alloy phase are preferable when a process for treating the byproducts containing arsenic is considered, in which the valuable elements will be recovered into the copper-rich alloy phase, while the less valuable iron eliminated into the iron-rich alloy phase.

The distribution ratios of silver, gold and platinum between the matte and copper-rich alloy $\left(\mathrm{L}_{1}\right)$ or iron-rich alloy $\left(\mathrm{L}_{2}\right)$ phases are shown in Fig. 5 in relation to the arsenic content in the matte for the $\mathrm{Cu}-\mathrm{Fe}-\mathrm{As}-\mathrm{C}$ system.

In the same way, the distribution ratio of a minor element $\mathrm{X}$ between the copper-rich alloy $\left(\mathrm{L}_{1}\right)$ and iron-rich alloy $\left(\mathrm{L}_{2}\right)$ phases is defined by.

$$
L_{\mathrm{X}}{ }^{\mathrm{L}_{1} / \mathrm{L}_{2}}=\langle\operatorname{mass} \% \mathrm{X}\rangle_{\mathrm{L}_{1}} /\langle\operatorname{mass} \% \mathrm{X}\rangle_{\mathrm{L}_{2}},
$$

The distribution ratios of silver and platinum are shown in Fig. 6 for the $\mathrm{Cu}-\mathrm{Fe}-\mathrm{S}-\mathrm{As}-\mathrm{C}$ system together with those obtained by the authors in the $\mathrm{Cu}-\mathrm{Fe}-\mathrm{As}-\mathrm{C}$ system ${ }^{9}$ in relation to the arsenic content in the copper-rich alloy phase.

As shown in Fig. 5, the distribution ratios of silver, gold and platinum between the matte and copper-rich alloy $\left(L_{1}\right)$ phases increase with increasing content of arsenic in the matte phase. It is noted that the distribution ratio at a given arsenic content in the matte decreases in the order of silver, platinum and gold. $L_{\mathrm{Ag}} \mathrm{m} / \mathrm{L}_{1}$ presents values of less than 1 , while $L_{\mathrm{Au}}{ }^{\mathrm{m} / \mathrm{L}_{1}}$ and $L_{\mathrm{Pt}}{ }^{\mathrm{m} / \mathrm{L}_{1}}$ very small values around $0.001 \mathrm{in}$ the whole range of arsenic content.

On the other hand, it is shown in the same figure that the distribution ratio between the matte and iron-rich alloy $\left(\mathrm{L}_{2}\right)$ phases at a given arsenic content in the matte decreases in the order of silver, gold and platinum. $L_{\mathrm{Ag}}{ }^{\mathrm{m} / \mathrm{L}_{2}}$ is almost constant at about 12 while $L_{\mathrm{Au}}{ }^{\mathrm{m} / \mathrm{L}_{2}}$ abruptly decreases and $L_{\mathrm{Pt}}{ }^{\mathrm{m} / \mathrm{L}_{2}}$ increases against the arsenic content in the matte.

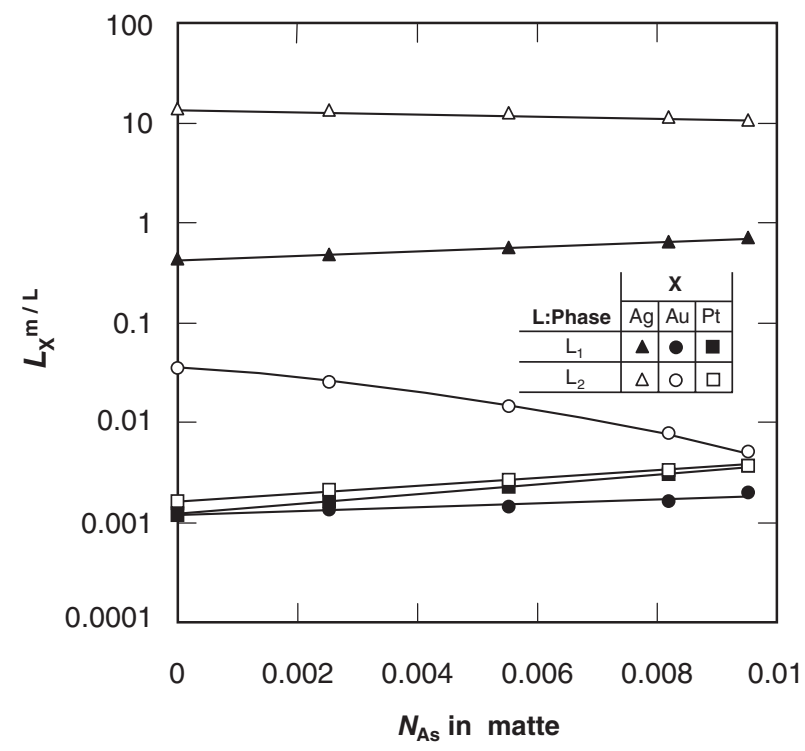

Fig. 5 Distribution ratios of silver, gold and platinum minor elements in relation to $N_{\mathrm{As}}$ in the matte in the Cu-Fe-S-As system saturated with carbon at $1473 \mathrm{~K}$.

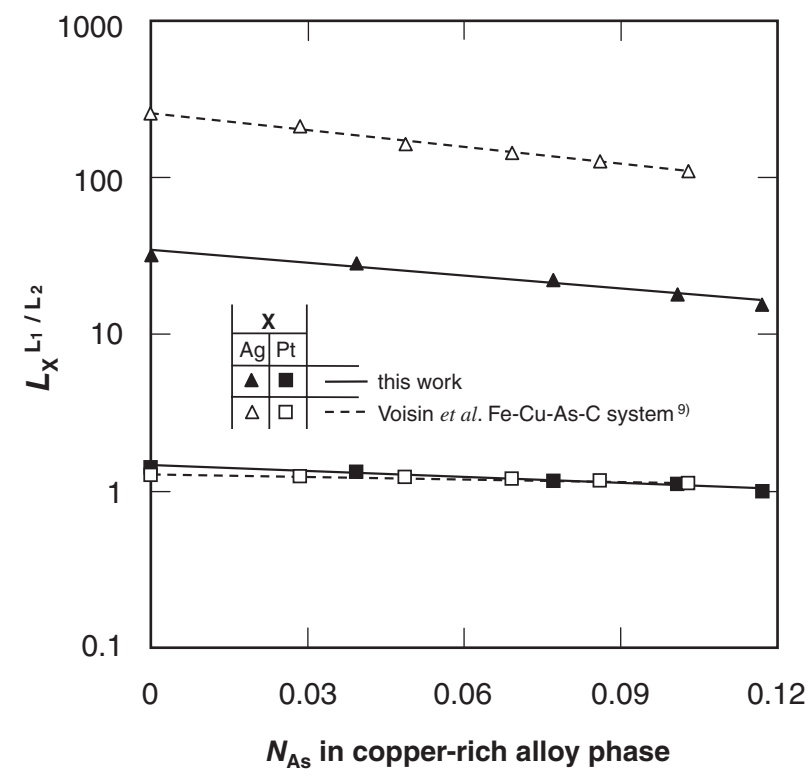

Fig. 6 Distribution ratios of silver and platinum between the copper-rich alloy $\left(\mathrm{L}_{1}\right)$ and iron-rich $\left(\mathrm{L}_{2}\right)$ alloy phases in relation to $N_{\mathrm{As}}$ in the copperrich alloy phase in the $\mathrm{Cu}-\mathrm{Fe}-\mathrm{S}-\mathrm{As}$ system saturated with carbon at $1473 \mathrm{~K}$.

As shown in Fig. 6, the distribution ratios of silver and platinum between the copper-rich alloy $\left(\mathrm{L}_{1}\right)$ and iron-rich alloy $\left(\mathrm{L}_{2}\right)$ phases in the $\mathrm{Cu}-\mathrm{Fe}-\mathrm{S}-\mathrm{As}-\mathrm{C}$ system decrease with increasing arsenic content in the copper-rich alloy phase. $L_{\mathrm{Ag}} \mathrm{L}_{1} / \mathrm{L}_{2}$ is larger than 10 while $L_{\mathrm{Pt}} \mathrm{L}_{1} / \mathrm{L}_{2}$ close to unity in the whole range of arsenic content. The distribution ratios of silver and platinum in the $\mathrm{Cu}-\mathrm{Fe}-\mathrm{As}-\mathrm{C}$ system obtained by the authors in a previous study ${ }^{9)}$ are also shown in Fig. 6 with broken lines. It is noteworthy in Fig. 6 that, in terms of the magnitude and the dependency against the arsenic content in the copper-rich alloy phase, $L_{\mathrm{Pt}^{2}} \mathrm{~L}_{1} / \mathrm{L}_{2}$ is very similar while $L_{\mathrm{Ag}} \mathrm{L}_{1} / \mathrm{L}_{2}$ is about 10 times larger than that for the $\mathrm{Cu}-\mathrm{Fe}-\mathrm{S}-$ As-C system. 


\section{Discussion}

\subsection{Activity coefficient of arsenic in three phases region of $\mathrm{Cu}-\mathrm{Fe}-\mathrm{S}-\mathrm{As}-\mathrm{C}$ system}

The thermodynamic properties of arsenic in the $\mathrm{Cu}-\mathrm{Fe}-\mathrm{S}$ As system saturated with carbon are of major concern for the phase relations in this system as well as the treatment of arsenic in the arsenic-rich matte produced from the copper concentrate containing a significant amount of this element. On the basis of the present data for the miscibility gap and the activities data for the $\mathrm{Cu}-\mathrm{Fe}-\mathrm{S}-\mathrm{As}$ system reported by other authors, ${ }^{4,5)}$ the Raoultian activity coefficient of arsenic in the matte phase in the miscibility gap where three phases are equilibrated in the $\mathrm{Cu}-\mathrm{Fe}-\mathrm{S}$-As system saturated with carbon at $1473 \mathrm{~K}$ was derived as follows.

Equation (3) is established in the equilibrium condition because of the same standard state for two liquid phases,

$$
\begin{aligned}
& \left\langle a_{\mathrm{As}}\right\rangle=\left\langle\gamma_{\mathrm{As}}\right\rangle\left\langle N_{\mathrm{As}}\right\rangle=\left[\gamma_{\mathrm{As}}\right]\left[N_{\mathrm{As}}\right]=\left[a_{\mathrm{As}}\right] \\
& {\left[a_{\mathrm{As}}\right]=\left[\gamma_{\mathrm{As}}\right]\left[N_{\mathrm{As}}\right]=\left\{\gamma_{\mathrm{As}}\right\}\left\{N_{\mathrm{As}}\right\}=\left\{a_{\mathrm{As}}\right\}}
\end{aligned}
$$

where $\gamma_{\mathrm{As}}$ and $N_{\mathrm{As}}$ are the Raoultian activity coefficient and the mole fraction of arsenic, and \langle\rangle$,[]$ and \{\} denote the copper-rich alloy, iron-rich alloy and matte phases, respectively.

The content of carbon in the copper-rich alloy phase for the investigated system was barely different from that indicated in the $\mathrm{Cu}-\mathrm{Fe}$ system saturated with carbon. ${ }^{11)}$ Since this value is very small, this phase can be treated as the $\mathrm{Cu}-\mathrm{Fe}-\mathrm{S}-\mathrm{As}$ quaternary system. Hence, $\left\langle\gamma_{\mathrm{As}}\right\rangle$ in eq. (3) is known by combining the reported activity data ${ }^{4,5)}$ in the corresponding quaternary system with the present data for the miscibility gap line in the copper-rich alloy phase. Then, $\gamma_{\mathrm{As}}$ in the ironrich alloy phase can be derived from eq. (3), in relation to the arsenic content. In the same way, once $\gamma_{\mathrm{As}}$ in the iron-rich alloy phase was determined by using the tie lines, which connect the iron-rich alloy and matte phases, $\gamma_{\mathrm{As}}$ in the matte phase was derived from eq. (4), in relation to the arsenic content in the matte.

The activity coefficients of arsenic (the standard state of activity is pure liquid arsenic) in the matte phase, $\left\{\gamma_{\mathrm{As}}\right\}$, of the miscibility gap, where three equilibrated phases coexist in the $\mathrm{Cu}-\mathrm{Fe}-\mathrm{S}$-As system saturated with carbon at $1473 \mathrm{~K}$, are shown in Fig. 7, in relation to the mole fraction of arsenic in the matte phase.

It is shown in Fig. 7 that $\log \left\{\gamma_{\text {As }}\right\}$ almost proportionally increases with $\left\{N_{\mathrm{As}}\right\}$, which can be expressed as

$$
\log \left\{\gamma_{\mathrm{As}}\right\}=-1.08+55.9\left\{N_{\mathrm{As}}\right\}
$$

with $\left\{\gamma^{\mathrm{o}}\right.$ As $\}$ of $8.33 \times 10^{-2}$ at infinite dilution. The activity coefficients of arsenic reported by Mendoza et al. ${ }^{4,5)}$ in the region, where the copper-rich alloy and matte phases are in equilibrium in the $\mathrm{Cu}-\mathrm{Fe}-\mathrm{S}$-As quaternary system, were also plotted in Fig. 7 with a broken line. It is noteworthy that, in terms of tendency, the activity coefficient is quite similar to that determined in this work for the $\mathrm{Cu}$-Fe-S-As-C system though about 1.5 times higher in magnitude. This discrepancy may be ascribed to the appearance of an iron-rich alloy phase with about 3-4 mass\% of carbon which is equilibrated with the copper-rich alloy and matte phases.

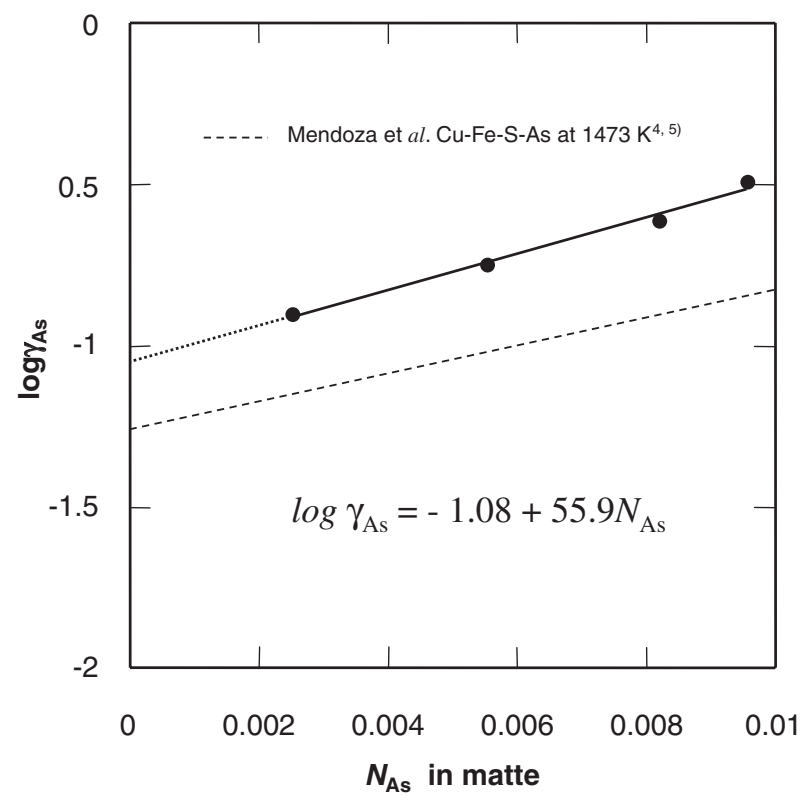

Fig. 7 Activity coefficient of arsenic in the matte phase in the miscibility gap of the $\mathrm{Cu}-\mathrm{Fe}-\mathrm{S}-\mathrm{As}$ system saturated with carbon at $1473 \mathrm{~K}$ (standard state: pure liquid As).

\subsection{Activity coefficient of arsenic in matte phase in equilibrium with iron-rich alloy phase in $\mathrm{Cu}-\mathrm{Fe}-\mathrm{S}$ - As-C systems}

It was assumed that the activity coefficient of arsenic in the $\mathrm{Cu}-\mathrm{Fe}-\mathrm{S}-\mathrm{As}-\mathrm{C}$ systems with $\mathrm{Fe}$ as a solvent and $\mathrm{Cu}, \mathrm{C}, \mathrm{S}$ and As as solutes might be expressed by eq. (6), which is valid when the higher order terms in Taylor's series expansion can be neglected. Although the mole fraction of carbon in the present iron-rich alloy phase is considerably high at about 0.16 , the application of eq. (6) to the present system was made, assuming that $\ln \gamma_{\text {As }}$ changes proportionally to $N_{\mathrm{C}}$ up to the saturation point of carbon.

$$
\begin{aligned}
\ln \gamma_{\mathrm{As}}= & \ln \gamma_{\mathrm{As}}{ }^{\mathrm{o}}+\varepsilon_{\mathrm{As}}{ }^{\mathrm{As}} N_{\mathrm{As}} \\
& +\varepsilon_{\mathrm{As}}{ }^{\mathrm{Cu}} N_{\mathrm{Cu}}+\varepsilon_{\mathrm{As}}{ }^{\mathrm{C}} N_{\mathrm{C}}+\varepsilon_{\mathrm{As}}{ }^{\mathrm{S}} N_{\mathrm{S}}
\end{aligned}
$$

where $\gamma_{\mathrm{As}}{ }^{\circ}$ is the limiting activity coefficient. $N_{\mathrm{As}}, N_{\mathrm{Cu}}, N_{\mathrm{C}}$ and $N_{\mathrm{S}}$, and $\varepsilon_{\mathrm{As}}{ }^{\mathrm{As}}, \varepsilon_{\mathrm{As}}{ }^{\mathrm{Cu}}, \varepsilon_{\mathrm{As}}{ }^{\mathrm{C}}$ and $\varepsilon_{\mathrm{As}}{ }^{\mathrm{S}}$ are mole fractions and interaction parameters of $\mathrm{As}, \mathrm{Cu}, \mathrm{C}$ and $\mathrm{S}$, respectively. First, $\gamma_{\mathrm{As}}{ }^{\mathrm{o}}, \varepsilon_{\mathrm{As}}{ }^{\mathrm{As}}, \varepsilon_{\mathrm{As}}{ }^{\mathrm{Cu}}$ and $\varepsilon_{\mathrm{As}}{ }^{\mathrm{C}}$ were fixed using the reported values of $\gamma_{\mathrm{As}}$ in the Fe-As binary as well as $\varepsilon_{\mathrm{As}}{ }^{\mathrm{C}}$ and $\varepsilon_{\mathrm{As}}{ }^{\mathrm{Cu}}$ which were determined by Voisin et al. ${ }^{9,12)}$ in the corresponding investigation, respectively. Then, $\varepsilon_{\mathrm{As}} \mathrm{S}$ in eq. (6) was derived by combining $\gamma_{\mathrm{As}}$ in the iron-rich alloy phase, previously calculated in 4.1 . The result is given in eq. (7), with $\varepsilon_{\mathrm{As}}^{\mathrm{S}}=23.3$.

$$
\ln \gamma_{\mathrm{As}}=-6+13 N_{\mathrm{As}}+7.3 N_{\mathrm{Cu}}+9.7 N_{\mathrm{C}}+23.3 N_{\mathrm{S}}
$$

By using eq. (7) and the compositional data for the iron-rich alloy phase, which were obtained in this study, $\gamma_{\mathrm{As}}$ in the iron-rich alloy phase in the $\mathrm{Cu}-\mathrm{Fe}-\mathrm{S}-\mathrm{As}-\mathrm{C}$ system can be determined.

Once $\gamma_{\text {As }}$ in the iron-rich alloy phase on the tie lines, which connect the iron-rich alloy and matte phases in the $\mathrm{Cu}-\mathrm{Fe}-\mathrm{S}$ As-C system, was determined, $\gamma_{\text {As }}$ in the matte phase with different matte grades can be derived from eq. (7), in relation to the arsenic content in the matte. The activity coefficient of 


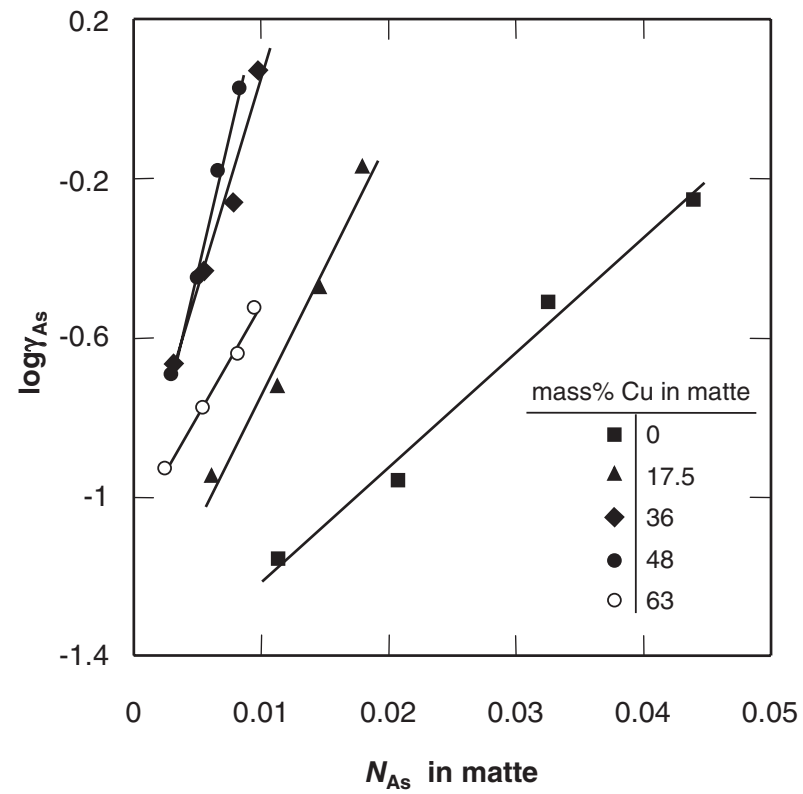

Fig. 8 Activity coefficient of arsenic in the matte phase in the region where the iron-rich alloy and matte phases coexist in the $\mathrm{Cu}$-Fe-S-As system saturated with carbon at $1473 \mathrm{~K}$ (standard state: pure liquid As).

arsenic (the standard state of activity is pure liquid arsenic) in the matte phase, $\left\{\gamma_{\mathrm{As}}\right\}$, in the region where the iron-rich alloy and matte phases coexist in the $\mathrm{Cu}-\mathrm{Fe}-\mathrm{S}$-As system saturated with carbon at $1473 \mathrm{~K}$ are shown in Fig. 8, in relation to the mole fraction of arsenic in the matte phase. It is noted in Fig. 8 that $\log \gamma_{\text {As }}$ increases proportionally with $N_{\text {As }}$ and that, at a given $N_{\mathrm{As}}, \gamma_{\mathrm{As}}$ in the matte without copper (matte grade is zero) is the smallest.

\subsection{Material balances in a proposed process for elimi- nating arsenic from arsenic-rich matte produced in copper smelting}

Based on the present experimental results, the material balances were evaluated for the new process proposed by the authors. Furthermore, laboratory experiments using industrial copper mattes doped with $\mathrm{Fe}_{2} \mathrm{As}$ were carried out to compare with the results of mass balance calculations.

It was supposed in the calculation that a given amount of copper matte with 70 mass $\%$ of $\mathrm{Cu}$, which contains 0.5 mass $\%$ of As and silver, gold and platinum with each 0.01 mass percent is treated by adding pig-iron at $1473 \mathrm{~K}$. The calculation was made by varying values of $\alpha$, which is given by $\alpha=$ (amount of added pig-iron)/(amount of initial copper matte), up to 0.5 . In the calculation, the loss of arsenic and sulfur by volatilization was neglected because the summation of equilibrium partial pressures of predominant As and $\mathrm{As}_{2}$ for arsenic and the partial pressure of $S_{2}$ for sulfur gas species over the corresponding alloys and matte at $1473 \mathrm{~K}$ are very small at less than 10 and $2 \mathrm{~Pa}$, respectively.., 13$)$

According to the results obtained in the present experiments, copper-rich and iron-rich alloys together with a matte with about 63 mass $\%$ of $\mathrm{Cu}$ are in equilibrium when $\alpha$ is over 0.065. The fractional distribution of copper, iron and arsenic as major components among the matte, iron rich alloy and copper rich alloy phases is shown on the left axis, while

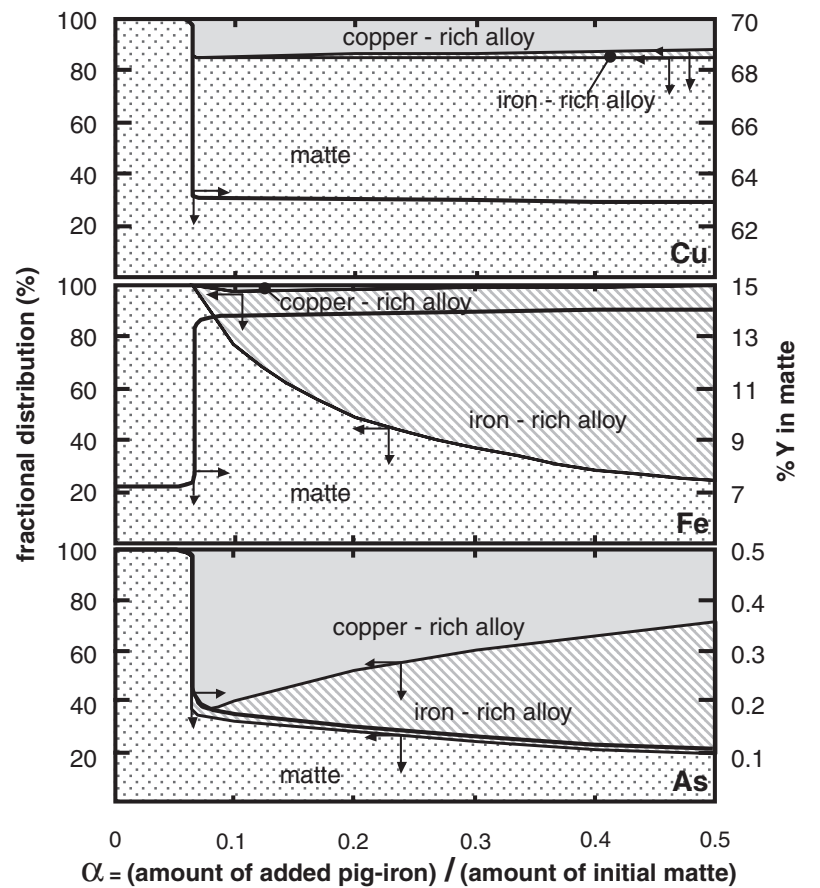

Fig. 9 Fractional distribution of major element $\mathrm{Y}(\mathrm{Y}$ : $\mathrm{Cu}, \mathrm{Fe}, \mathrm{As})$ among the copper-rich alloy, iron-rich alloy and matte phases and its mass $\%$ in the matte phase against $\alpha$.

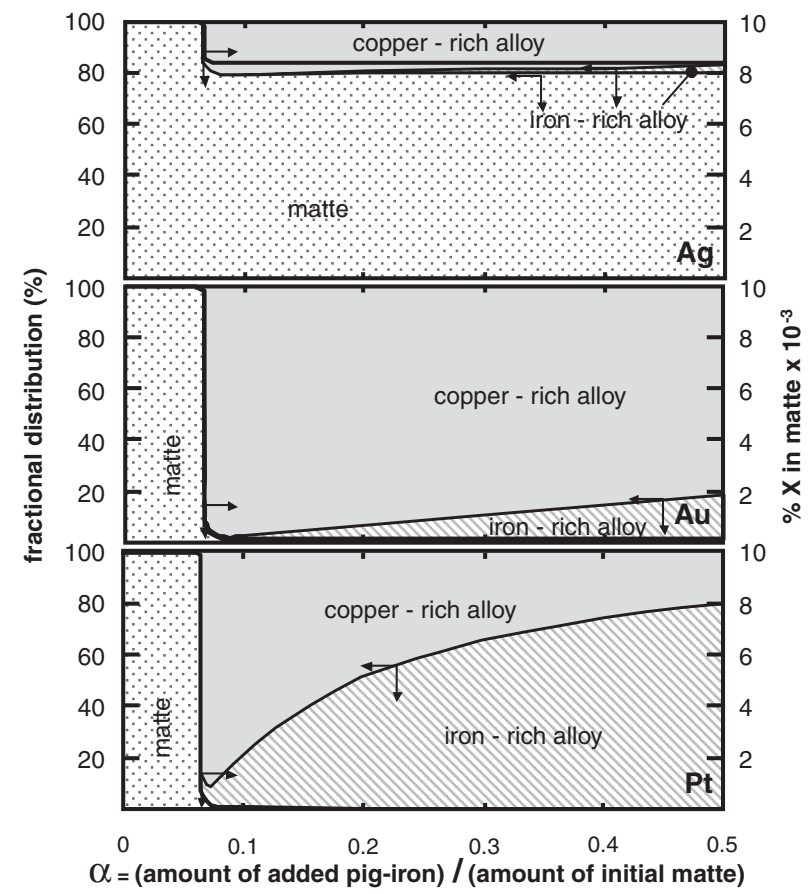

Fig. 10 Fractional distribution of precious minor element $\mathrm{X}$ (X: Ag, Au, Pt) among the copper-rich alloy, iron-rich alloy and matte phases and its mass $\%$ in the matte phase against $\alpha$.

mass $\%$ of these elements in the treated matte on the right axis, in relation to $\alpha$ in Fig. 9. While those of silver, gold and platinum as precious minor elements are shown in Fig. 10. Since carbon and sulfur are mostly distributed in the iron-rich alloy and matte phases, respectively, their results are not shown in Figs. 9 and 10. 
Table 3 Fractional distribution (\%) in the treatment of industrial copper matte by adding pig-iron at $1473 \mathrm{~K}$.

\begin{tabular}{|c|c|c|c|c|c|c|c|c|c|}
\hline \multirow[b]{2}{*}{$\alpha$} & \multicolumn{3}{|c|}{ copper-rich alloy phase $\left(\mathrm{L}_{1}\right)$} & \multicolumn{3}{|c|}{ iron-rich alloy phase $\left(\mathrm{L}_{2}\right)$} & \multicolumn{3}{|c|}{ matte phase } \\
\hline & $\mathrm{Fe}$ & As & $\mathrm{Cu}$ & $\mathrm{Fe}$ & As & $\mathrm{Cu}$ & $\mathrm{Fe}$ & As & $\mathrm{Cu}$ \\
\hline 0.2 & 1.43 & 47.29 & 13.69 & 49.21 & 24.52 & 0.89 & 49.36 & 28.19 & 85.42 \\
\hline 0.3 & 1.03 & 39.85 & 13.35 & 61.02 & 35.71 & 1.51 & 37.95 & 24.44 & 85.14 \\
\hline 0.4 & 0.78 & 33.30 & 12.79 & 70.56 & 45.55 & 2.19 & 28.66 & 21.15 & 85.02 \\
\hline
\end{tabular}

For the major components, as shown in Fig. 9, with increasing value of $\alpha$ from 0.1 to 0.5 , the fractional distribution of copper decreases from 15 to $11.9 \%$, increases from 0.24 to $2.81 \%$ and is almost constant at about $85 \%$ in the copper-rich alloy, iron-rich alloy and matte phases, respectively. The matte grade (mass $\%$ of $\mathrm{Cu}$ ) in the treated matte is constant at about 63 mass percent. For iron, the fractional distribution decreases from 2.5 to $0.6 \%$ and from 76.9 to $24.3 \%$ in the copper-rich alloy and matte phases, respectively, while increases from 20.6 to $75.1 \%$ in the ironrich alloy phase. For arsenic, the fractional distribution decreases from 60.1 to $28.1 \%$ and from 32.4 to $19.2 \%$ in the copper rich alloy and matte phases, respectively, while increases from 7.5 to $52.7 \%$ in the iron-rich alloy phase. The content of arsenic in the treated matte at $\alpha$ of 0.1 is 0.18 mass $\%$.

For the precious minor elements, as shown in Fig. 10, with increasing value of a, the fractional distribution of platinum in the copper-rich alloy abruptly decreases and those of silver and gold slightly decrease. On the contrary, the fractional distribution of platinum in the iron-rich alloy phase increases and those of silver and gold decrease. In the matte phase, the fractional distribution of platinum slightly decreases while those of silver and gold are almost constant.

The experimental results using industrial copper matte doped with $\mathrm{Fe}_{2} \mathrm{As}(\mathrm{Cu}=70, \mathrm{Fe}=7.54, \mathrm{~S}=19.4$, As = 0.5, others $=2.56$ mass percent) are shown in Table 3 . They are in a good agreement with those in the material balance calculations. These results suggest that, the recovery of valuable copper, silver and gold into the copper-rich alloy phase as well as the elimination of less valuable iron together with the detrimental arsenic into the iron-rich alloy phase might be feasible even though the proportion of valuable platinum lost in the iron-rich alloy phase is considerably large. The copper-rich alloy may be further treated in a pyrometallurgical or hydrometallurgical process to extract silver, gold and copper; the iron-rich alloy phase may be harmlessly encapsulated in a small volume and discarded if the content of platinum in the initial charge is small, while the matte phase might be continuously processed in the following converting stage.

\section{Summary}

As a fundamental study for eliminating arsenic from the arsenic-rich matte produced from the copper concentrate containing a significant amount of arsenic and for treating speiss which is a by-product with a considerably high content of arsenic in nonferrous smelting processes, the phase relations in the $\mathrm{Cu}-\mathrm{Fe}-\mathrm{S}$ and $\mathrm{Cu}-\mathrm{Fe}-\mathrm{S}-\mathrm{As}$ systems saturated with carbon and the distribution of some minor elements between the phases in the miscibility gap, where three equilibrated phases coexist, were investigated at $1473 \mathrm{~K}$. On the basis of the obtained results, material balance calculations and laboratory experiments using industrial copper matte were made in order to deepen the development of the new proposed process. The results are summarized as follows:

(1) The phase relations in the $\mathrm{Cu}-\mathrm{Fe}-\mathrm{S}-\mathrm{C}$ quaternary system are similar to those in the $\mathrm{Cu}-\mathrm{Fe}-\mathrm{S}$ ternary system.

(2) Arsenic has strong preference to the alloy phases and carbon is distributed almost completely in the iron-rich alloy phase. In the region where iron-rich alloy and matte phases are in equilibrium, arsenic is preferentially distributed in the iron-rich phase. This effect increases when the matte grade is increased in the system.

(3) Raoultian activity coefficient of arsenic in the matte phase with a matte grade of 63 mass $\%$ of $\mathrm{Cu}$ is around 0.08 , while $\log \gamma_{\mathrm{As}}$ increases proportionally with $N_{\mathrm{As}}$ in the matte phase in equilibrium with the iron-rich alloy in the $\mathrm{Cu}-\mathrm{Fe}-\mathrm{S}$-As system saturated with carbon.

(4) In the region where the matte $(\mathrm{m})$, copper-rich alloy $\left(\mathrm{L}_{1}\right)$ and iron-rich alloy $\left(\mathrm{L}_{2}\right)$ phases coexist, $L_{\mathrm{Ag}} \mathrm{m} / \mathrm{L}_{1}$ is less than 1 and $L_{\mathrm{Ag}} \mathrm{m} / \mathrm{L}_{2}$ larger than $10, L_{\mathrm{Au}}^{\mathrm{m} / \mathrm{L}_{1}}$ is around 0.001 and $L_{\mathrm{Au}}^{\mathrm{m} / \mathrm{L}_{2}}$ less than 0.1 , while $L_{\mathrm{Pt}}{ }^{\mathrm{m} / \mathrm{L}_{1}}$ and $L_{\mathrm{Pt}}{ }^{\mathrm{m} / \mathrm{L}_{2}}$ are very similar at about 0.001 . These suggest that most gold and a large part of silver will be enriched in the copper-rich phase while platinum in both metal phases.

(5) For the treatment of arsenic-rich matte produced in copper smelting by adding the pig-iron, the recovery of valuable copper, silver and gold into the copper-rich alloy phase as well as the elimination of iron and arsenic into the iron-rich alloy phase might be feasible. The elimination of arsenic increases with increasing pig-iron amount in the charge.

(6) Since the experimental results obtained in this investigation using industrial mattes agreed very well with those in the material balance calculation, may be an important way to predict the behavior of arsenic-rich matte produced in copper processes when they are treated by using pig iron at $1473 \mathrm{~K}$.

\section{REFERENCES}

1) K. Itagaki, M. Hino and A. Yazawa: Erzmetall 36 (1983) 59-64.

2) K. Itagaki, Y. H. Lee and A. Yazawa: Erzmetall 37 (1984) 179-183.

3) H. Jalkanen, J. Vehvilainen and Poijarvi: Scandinavian Journal of Metallurgy 32 (2003) 65-70.

4) D. Mendoza, M. Hino and K. Itagaki: Mater. Trans. 43 (2002) 11661172.

5) D. Mendoza, M. Hino and K. Itagaki: J. Min. Mater. Process. Inst. Japan 118 (2002) 197-201.

6) K. Itagaki and A. Yazawa: Trans. JIM 23 (1982) 759-767. 
7) K. Itagaki and A. Yazawa: Proceedings of the 1983 International Sulfide Smelting Symposium, San Francisco, California, TMS-AIME 1 (1983) 119-142.

8) J. Dobrzanski and W. Kozminski: Proceedings of Copper 2003, IV, Santiago, Chile, (2003) 239-252

9) L. Voisin, H. M. Henao and K. Itagaki: Mater. Trans. 45 (2004) 28512856.

10) C. Wang, J. Hirama, T. Nagasaka and S. Ban-Ya: ISIJ International 31 (1991) 1292-1299.
11) Y. Chang, J. Newmann, A. Mikula and D. Goldberg: INCRA Series on the Metallurgy of Copper - Phase Diagrams and Thermodynamic Properties of Ternary Copper-Metal Systems, (International Copper Research Association, Milwaukee, Wisconsin, USA, 1979) 367-386.

12) L. Voisin, H. M. Henao, M. Hino and K. Itagaki: Mater. Trans. 46 (2005) 3030-3036.

13) A. Zakeri, M. Hino and K. Itagaki: J. Min. Mater. Process. Inst. Japan 17 (2000) 43-60. 